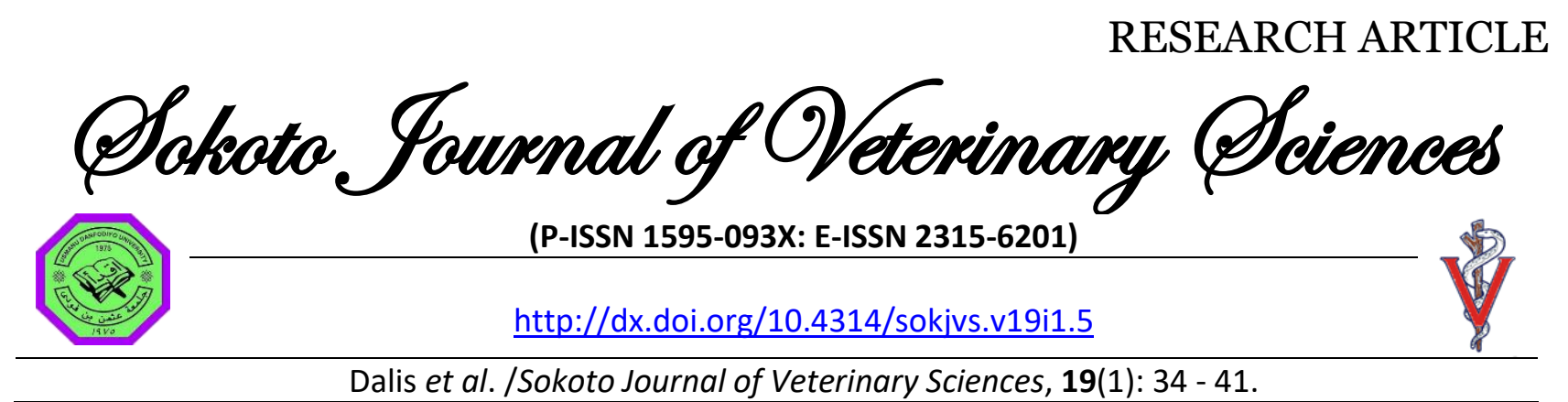

\title{
Magnitude and risk factors associated with bovine dermatophilosis in Sabon-Gari, Kaduna state and Jos, Plateau state, Nigeria
}

\author{
JS Dalis ${ }^{1 *}$, HM Kazeem $^{1}$, MY Fatihu² \& AA Makinde ${ }^{3}$ \\ 1. Department of Veterinary Microbiology, Faculty of Veterinary Medicine, Ahmadu Bello University, Zaria, Nigeria \\ 2. Department of Veterinary Pathology, Faculty of Veterinary Medicine, Ahmadu Bello University, Zaria, Nigeria \\ 3. Dermatophilosis Research Division, National Veterinary Research Institute, Vom, Nigeria
}

*Correspondence: Tel.: + 234 8069299910; E-mail: dalisjames280@yahoo.com

\begin{abstract}
Copyright: (c) 2021 Dalis et al. This is an open-access article published under the terms of the Creative Commons Attribution License which permits unrestricted use, distribution, and reproduction in any medium, provided the original author and source are credited.

Abstract

Dermatophilosis is a contagious zoonotic skin disease affecting a variety of domestic and wild animals with grave economic consequences. The status of bovine dermatophilosis and associated risk factors in Sabon-Gari, Kaduna State and Jos, Plateau State, Nigeria are yet to be fully determined. The aim of this study was to determine the prevalence of bovine dermatophilosis in Sabon-Gari and Jos. One thousand, nine hundred and twenty skin scab samples consisting of 1,530 from Sabon-Gari and 390 from Jos were obtained from cattle having cutaneous lesions including papules, exudative dermatitis with matting of the hair, cream colored, thickly crusted and scabby lesions suggestive of Dermatophilus infection. Smears were made from the underneath surface of each specimen on a clean glass slide, air dried, heat fixed and Gram stained. The stained smears were examined microscopically for Gram-positive filamentous organism having both longitudinal and transverse division, typical of Dermatophilus congolensis. Further identification was done by isolating the causative agent in $5 \%$ de-fibrinated sheep blood agar. Data were analyzed using tables, percentages and Chi square test. P-values less than or equal to 0.05 were considered significant. One hundred and forty-six $(9.5 \%)$ and $21(5.4 \%)$ of the samples from Sabon-Gari and Jos respectively were positive for $D$. congolensis.

Publication History: The overall prevalence of bovine dermatophilosis in Sabon-Gari and Jos was 8.7\% Received: 11-10-2020

Revised: $26-12-2020$

Accepted: 05-01-2021 $(167 / 1,920)$, respectively. Breed, age, management practice and season were found to be significant risk factors associated with bovine dermatophilosis. Methods for control of the disease in cattle as well as prevention of human exposure were highlighted.
\end{abstract}




\section{Introduction}

Dermatophilosis is a contagious, zoonotic skin disease caused by a Gram-positive filamentous Actinomycete, Dermatophilus congolensis. Although the disease affects a wide range of domesticated and wild animals including humans (Aubin et al., 2016), it is however, more common among cattle, goats, sheep and horses especially those in tropical and subtropical countries having warm and humid climatic conditions (Hargis \& Myers, 2017). Dermatophilosis is transmitted by direct contact between clinically infected animals, asymptomatic carrier animals or fomites (Adedeji \& Adene, 2017). The spores of $D$. congolensis can remain infective for several months on skin, hair, and dried crusts from healed lesions until climatic conditions are favorable (Zaria, 1993). The bacterium multiplies by growth of hyphae that undergo transverse and longitudinal division to produce filaments containing packets of cocci (Skalka \& Pospisil, 1994). Moisture causes the release of motile, infective zoospores from the scabs or crusts which could establish new sites of infection on the same animal or are transmitted to new hosts (Brian \& Larry, 2013).

It has been found that chronic lesions as observed under field conditions do not establish through experimental infection with $D$. congolensis in the laboratory, suggesting that the organism itself is not highly pathogenic (Lunn et al., 2016). Therefore, a combination of factors is necessary for the development of clinical lesions (Lunn et al., 2016).

Dermatophilosis has a world-wide distribution and is associated with high economic losses in the livestock and leather industries especially in tropical Africa and Nigeria in particular (Zaria, 1993; Abdullahi, 2001; Makinde, 2004). Losses have been attributed mainly to the downgrading of hides and skin, reduced meat and milk production and poor growth rate in suckling calves (Dalis et al., 2007).

The occurrence of dermatophilosis in animals may vary from one location to another. For instance, Bida \& Kelley (1976) examined 1,785 cattle and found a prevalence of $12 \%$. Nath et al. (2010) working in Bangladesh, examined 1, 830 cattle and found a prevalence of $13.55 \%$ while Maruthi et al. (2017) reported a prevalence of $14.99 \%$ when 727 animals including 148 cattle and 579 buffalos were examined in Andhra Pradesh.

In spite of the grave economic consequence of dermatophilosis on the livestock and leather industries, there have not been much coordinated efforts at studying the prevalence of the disease among the cattle population in most parts of northern Nigeria, since the report of Bida \& Kelley (1976).

This paper describes the prevalence as well as risk factors associated with bovine dermatophilosis in Sabon-Gari and Jos, Nigeria.

\section{Materials and Methods}

Study area

This study was conducted on cattle in Sabon-Gari, Kaduna State and Jos, Plateau state, Nigeria.

Sampling locations: Zango, Shika, Wuchichili, Abu Farm, Hayin Liman, Kwangila and Samaru in SabonGari and Kaduna Vom, Jos Abattoir, Jos Cattle Market and Bukuru in Jos were selected by simple random sampling technique (Thrusfield, 1997) by balloting. Samples were collected based on a crosssectional study in which sampling units were selected using the purposive sampling technique described by Martin et al. (1997). Briefly, after wearing protective equipment (cap, Laboratory coat, cap and mask), all the cattle in the herd were physically examined by visual inspection and palpation. Only animals that were found with clinical lesions such as papules, serous exudation with hairs matted together resembling a paint brush, cream colored, thickly crusted and scabby skin lesions or accumulations of keratinized cutaneous material forming wart-like lesions suggestive of dermatophilosis (Hargis \& Myers, 2017) were included.

A total of 1,920 skin scabs (1,530 from Sabon-Gari and 390 from Jos) were aseptically collected from suspected animals. The scabs were removed using sterile forceps into sterile Petri-dishes. Breed, sex, age of animal (young $<1$ year and adult $>1$ year), management practice, season and location were recorded. Samples were transported to the Department of Veterinary Microbiology, Ahmadu Bello University, Zaria, and stored at room temperature until analyzed.

\section{Laboratory examination}

Direct microscopic examination: Direct examination of skin scabs was performed as described by Quinn et al. (1999). Briefly, impression smears were made from moist, soft materials obtained from the concave surface of the scabs on clean grease-free glass slides. Dry scabs from chronic lesions were softened by soaking in sterile water and smears made by firmly pressing the underneath surfaces on to glass slides. The slides were allowed to dry in air, heat fixed and stained with Gram stain. The stained 
smears were examined at $\times 1000$ using oil immersion lens of a light microscope (Nikon, ECLIPSE-E100, 824592, China). The presence of Gram-positive filamentous, branching organism having both transverse and longitudinal septa was considered positive for $D$. congolensis

Isolation of etiologic agent in culture: All the samples including those that were positive and those that were negative by direct examination were processed for isolation of $D$. congolensis using the modified Haalstra's technique as described by Van Breuseghem et al. (1976). Briefly, one gram of each specimen was minced with a sterile scalpel blade and placed in sterile Bijou bottles containing five milliliters of sterile water. The bottles were closed loosely and incubated at $37{ }^{\circ} \mathrm{C}$ in $10 \%$ carbon dioxide for 30 minutes. One loopful from the surface fluid from each of the bottles was inoculated on to plates containing $5 \%$ de-fibrinated sheep blood agar and incubated at $37{ }^{\circ} \mathrm{C}$ in $10 \%$ carbon dioxide for 48 h. The plates were examined for small, betahemolytic colonies that are pitted into the medium. Smears were made from suspected colonies, Gramstained and examined at x1000 using oil immersion objective of a light microscope (Nikon, ECLIPSE-E100, 824592, China) for presence of Gram- positive filamentous organism that divides transversely and longitudinally consisting of four or more transverse rows of cocci.

\section{Statistical analysis}

Data were presented in tables and percentages. Chisquare method was used to test for association between bovine dermatophilosis and some risk factors while Odds ratio was used to estimate the strength of association between the factors and the disease.

Data were analyzed using SPSS version 21 (IBM, USA). P-values less than or equal to 0.05 were considered significant.

\section{Results}

\section{Clinical signs}

Affected animals showed greasy, cream colored, thickly crusted skin lesions that were firmly attached to the hair fibers (plate I).

\section{Direct microscopic examination of skin scabs}

Out of the 1,920 skin scabs examined by direct microscopy, 167 (8.7\%) showed Gram-positive filaments which were transversely and longitudinally divided to form chains of cocci in multiple rows typical of $D$. congolensis (plate II).
Isolation of $D$. congolensis in culture

Of the 1,920 skin scabs processed for culture, 159 $(8.3 \%)$ were positive for $D$. congolensis.

All the samples that were negative by direct examination were also negative by culture. Colonies on $5 \%$ de-fibrinated sheep blood agar were small, grayish-white, beta-hemolytic and firmly adherent to the medium.

Prevalence rate of bovine dermatophilosis in SabonGari and Jos, Nigeria

Out of the 1,530 cattle with skin lesions in SabonGari, 146 (9.5\%) were positive for dermatopilosis while $21(5.4 \%)$ of the 390 animals in Jos were positive for the disease. There was no significant difference in the prevalence of the disease between Sabon-Gari and Jos ( $p>0.05)$. The overall prevalence of bovine dermatophilosis in Sabon-Gari and Jos was 8.5\% (167/1920) (Table 1).

Prevalence of bovine dermatophilosis based on breed, sex, age, management practice, and season in Sabon-Gari and Jos, Nigeria

Breed: Out of the 1,920 samples examined, 1,761 were obtained from Bunaji breed of cattle while 159 were from Friesian cross breed. One hundred and eighteen (6.7\%) Bunaji and 49 (30.8\%) Friesian cross breed tested positive for dermatophilosis. The prevalence of the disease was significantly higher in the Friesian cross than the Bunaji breed $(p<0.05)$.

Sex: From the 1,920 specimens analyzed, 385 were from males while 1,535 were from female animals. Thirty-eight (9.9\%) Males and 129 (8.4\%) females tested positive for dermatophilosis. There was no significant difference in the occurrence of the disease between male and female animals ( $p>0.05)$.

Age: Of the 1,920 samples processed for bacteriology, 1,600 were from adult cattle (>1year) while 320 were from young animals ( $\leq 1$ year). One hundred and forty-two (8.9\%) adult and 25 (7.8\%) young animals were positive for $D$. congolensis. The prevalence of dermatophilosis was significantly higher in adult than young cattle $(p<0.05)$.

Management Practice: Out of the 1,920 specimens tested, 538 were obtained from confined cattle while 1,382 were from unconfined animals. Thirtyone (5.8\%) and 136 (9.8) confined and unconfined cattle respectively were positive for dermatophilosis. The occurrence of the disease was significantly higher in unconfined than confined animals $(p<0.05)$. 


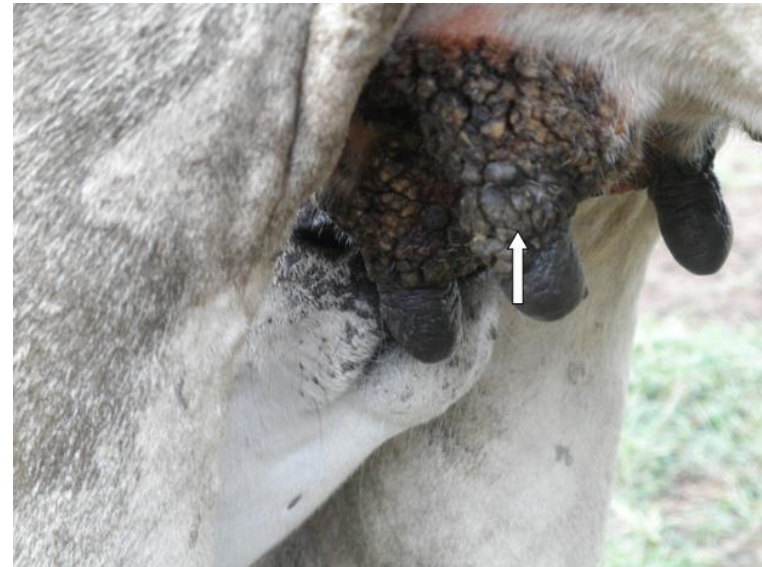

Plate I: A White Fulani cow affected by dermatophilosis. Note the thick, crusty and scabby lesions involving the udder and teats (arrow)

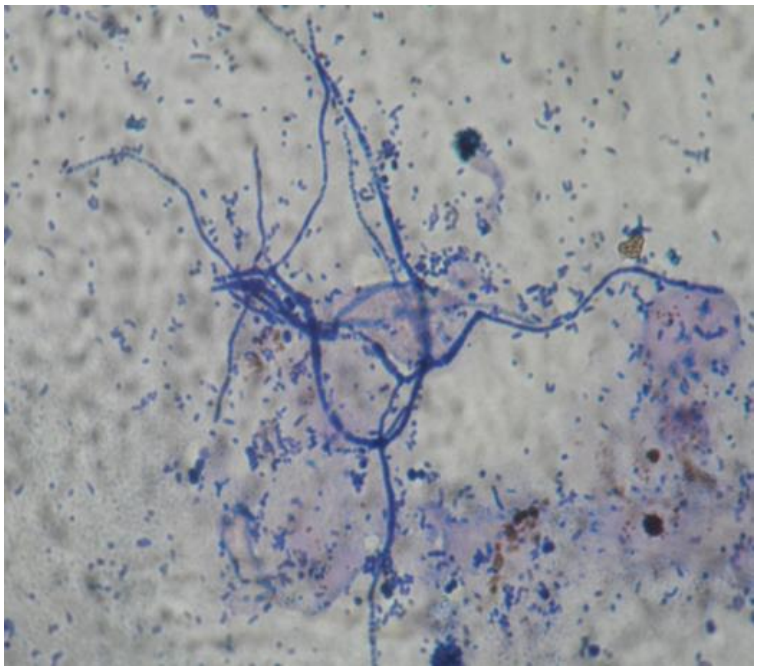

Plate II: Microscopic morphology of $D$. congolensis stained with Gram stain (x1000). Note the Grampositive, narrow, branching filaments with transverse and longitudinal septation forming parallel rows of cocci.

Table 1: Prevalence of bovine dermatophilosis in Sabon Gari and Jos, Nigeria

\begin{tabular}{llll}
\hline Locality & $\begin{array}{l}\text { No. of animals } \\
\text { with skin lesions }\end{array}$ & $\begin{array}{l}\text { No. of animals Positive for } \\
\text { D. congolensis }\end{array}$ & $\begin{array}{l}\text { Prevalence of } \\
\text { Dermatophilosis (\%) }\end{array}$ \\
\hline Sabon Gari & & 52 & 5.8 \\
Zango & 900 & 68 & 24.3 \\
Shika & 280 & 8 & 6.2 \\
Wuchichili & 130 & 8 & 12.3 \\
Abu Farm & 65 & 2 & 2.5 \\
Hayin Liman & 80 & 4 & 26.7 \\
Kwangila & 15 & 4 & 6.7 \\
Samaru & 60 & 146 & 9.5 \\
Sub Total & 1530 & & \\
Jos & & 6 & 12.0 \\
Kaduna Vom & 50 & 7 & 3.5 \\
Jos Abattoir & 200 & 4 & 5.0 \\
Jos Cattle Market & 80 & 4 & 6.7 \\
Bukuru & 60 & 21 & 5.4 \\
Sub Total & 390 & 167 & 8.7 \\
Grand Total & 1,920 & & \\
\hline
\end{tabular}

$\chi^{2}=0.23 ; P>0.05, O R=1.8$

Season: Of the 1,920 samples examined for dermatophilosis, 1,023 were obtained during the rainy season while 897 were collected during the dry season. One hundred and sixteen (11.3\%) and 51 (5.7\%) cattle tested positive during the rainy and dry seasons respectively. The prevalence of the disease was significantly higher during the rainy than dry season $(p<0.05)$ (Table 2$)$.

\section{Discussion}

In this study, the prevalence of bovine dermatophilosis in Sabon Gari and Jos were 9.5\% and $5.4 \%$ respectively. The overall prevalence of the disease was $8.7 \%$ which compares to the findings of Zaria (1993) who reported that the prevalence of dermatophilosis in domesticated ruminants may vary widely between different parts of northern Nigeria, but is generally within the range of 5 and $10 \%$. Analysis of the results based on locations showed that there was no significant difference in occurrence of bovine dermatophilosis between Sabon-Gari and Jos ( $p>0.05$ ), even though there was a higher prevalence of the disease in Sabon Gari than Jos. This may be due to the warm and humid 
Table 2: Prevalence of bovine dermatophilosis based on selected demographic and climatic variables in Zaria and Jos, Nigeria

\begin{tabular}{|c|c|c|c|c|c|c|}
\hline Variables & Total & Positive & Prevalence rate (\%) & $\chi^{2}$ & OR & P-value \\
\hline \multicolumn{7}{|l|}{ Breed } \\
\hline Bunaji & 1.761 & 118 & 6.7 & 5.0 & $0.1612^{*}$ & 0.02535 \\
\hline Friesian cross & 159 & 49 & 30.8 & & & \\
\hline \multicolumn{7}{|l|}{ Sex } \\
\hline Male & 385 & 38 & 9.9 & 3.27 & 1.1936 & 0.07056 \\
\hline Female & 1,535 & 129 & 8.4 & & & \\
\hline \multicolumn{7}{|l|}{ Age } \\
\hline Adult (>1year) & 1,600 & 142 & 8.9 & 4.1 & $1.1492 *$ & 0.04288 \\
\hline Young ( $\leq 1$ year) & 320 & 25 & 7.8 & & & \\
\hline \multicolumn{7}{|l|}{ Management } \\
\hline Confined & 538 & 31 & 5.8 & 7.6 & $0.5602 *$ & 0.00584 \\
\hline Not confined & 1,382 & 136 & 9.8 & & & \\
\hline \multicolumn{7}{|l|}{ Season } \\
\hline Rainy season & 1,023 & 116 & 11.3 & 18.5 & $2.1215^{*}$ & 0.00002 \\
\hline Dry season & 897 & 51 & 5.7 & & & \\
\hline
\end{tabular}

$\mathrm{OR}=$ Odds ratio

* = Statistically significant OR

climatic conditions of Sabon Gari in contrast to the cold, near temperate climate of Jos.

The diagnosis of bovine dermatophilosis in this report was based on clinical signs, direct microscopic examination and isolation of $D$. congolensis in culture. The main clinical signs observed were consistent with the report of Hargis \& Myers (2017). However, the lesions of bovine dermatophilosis are not always specific and must be differentiated from other clinically similar skin diseases such as dermatophytosis and demodecosis (Moriello, 2013). The presence of Gram-positive, filamentous organism which was transversely and longitudinally divided to form chains of cocci in multiple rows in this report concurs with the reports of Gordon (1964), Skalka \& Pospisil (1994) and O.I.E (2019). This characteristic morphology has been described by O.I.E (2019) as diagnostic for dermatophilosis. However, some specimens may not contain intact filaments, and hence, cannot be distinguished morphologically from other coccoid bacteria. In this circumstance, isolation of the etiologic agent in culture is critical for confirmation of diagnosis.

The colonial appearance of $D$. congolensis in this study is consistent with those reported previously (Abu-Samra, 1978; Mannan et al., 2009; Amor et al., 2011), However, colonial morphology of $D$. congolensis may vary from one strain to another. Gordon (1964) in a study of the Genus Dermatophilus, found great variation in colonial morphology such that a single strain often gave rise to diverse forms under varying conditions and even on the same plate. Although the morphology of $D$. congolensis in culture is similar to colonies produced by other closely related Actinomycete such as Streptomyces and Nocarcadia species, nevertheless, these close relatives of $D$, congolensis do not produce filaments that break up into multiple rows of cocci (O.I.E., 2019).

The low isolation rate of $D$. congolensis in culture $(159 / 1,920 ; 8.3 \%)$ compared to $D$. congolensis positive by direct examination $(167 / 1,920 ; 8.7 \%)$ suggests that the direct microscopical examination of skin scabs may be a more sensitive test than isolation of the organism in culture and confirms the report by Abdullahi (2001) who found more positive cases by direct examination than by culture. This may be due to frequent contamination of cultures by growth of secondary bacteria. It is generally believed that samples submitted to the laboratory for isolation of $D$. congolensis are usually contaminated with various bacteria species such as Staphylococcus, Streptococcus, Micrococcus, Pseudomonas, Proteus and Escherichia coli (Awad et al., 2008; Dalis et al., 2010).

The presence of dermatophilosis which was significantly higher $(\mathrm{P}<0.05 \%)$ in Friesian crossbreed than the Bunaji breed of cattle concurs with the report of Admassu \& Alemu (2011) who found significantly higher prevalence of dermatophilosis in cross bred cattle than the indigenous Zebu cattle $(p<0.05)$ when 3,456 cattle including 3,181 indigenous Zebu and 275 Holsteins-Zebu crosses were studied in north-western Ethiopia. It is however, at variance with the report of Nath et al. (2010) who found significantly higher prevalence in 
the indigenous breed of cattle than the Holstein and its crosses $(P<0.01)$ in Bangladesh.

In this study, there was no significant difference in the occurrence of dermatophilosis between male and female cattle $(p>0.05)$, which confirms the report of (Bayisa et al., 2012). It is however, at variance with the reports of Nath et al. (2010) who found significantly higher prevalence in males than females $(p<0.01)$ in Bangladesh, and Kumar et al. (2018) who reported significantly higher prevalence in female than male cattle $(P<0.05)$ in India.

The significantly higher prevalence of the disease in adult than young animals $(P<0.05)$ in this study concurs with the findings of Admasu \& Alemu (2011) and Bayisa et al. (2012) but is sharply contrasted by the report of Siva \& Vijaye (2015) who found significantly higher prevalence in young than adult animals $(P<0.01)$ when 727 animals including 148 cattle and 579 buffalos where examined in Andhra Pradesh. However, other investigators (Macadam, 1976 , Oppong, 1976) are of the opinion that there is no age susceptibility and that adult and young animals are equally susceptible. The higher occurrence of dermatophilosis in adult than young animals may be closely related to the husbandry practice. Most adult cattle are usually grazed on the field from morning until evening when they are brought back to the pens. This practice exposes the adult animals to environmental factors such as thorny bushes, excessive wetting by rain water, ticks and other biting insects and hence more likely to acquire Dermatophilus infection than young animals that are usually confined and fed in the pens. It may be for the same reason that the prevalence of dermatophilosis was significantly higher in unconfined than confined animals $(P<0.05)$ which is consistent with the report of Nath et al. (2010).

Similarly, significantly higher prevalence of bovine dermatophilosis was found in the rainy than dry season $(p<0.05)$ which is similar to the reports of Admassu \& Alemu (2011); Bayisa et al. (2012) and Siva \& Vijaya (2015). This may be because rain water causes maceration of the stratum corneum and thus, facilitating the attachment of zoospores to the skin to allow $D$. congolensis to cause clinically severe dermatophilosis (Ambrose et al., 1999). Furthermore, high humidity due to heavy rainfall also contributes indirectly to the spread of lesions by allowing increase in the number of biting insects particularly flies and ticks, which act as mechanical vectors and therefore predispose animals to dermatophilosis (Radostits et al., 2007).

Apart from its zoonotic potential, Dermatophilus infection in cattle can assume epizootic proportion especially during the rainy season with attendant grave economic losses (Bayisa et al., 2012).

In conclusion, the prevalence of bovine dermatophilosis was $9.5 \%$ and $5.4 \%$ in Sabon Gari and Jos respectively, indicating that the disease is a health problem among cattle in the study area.

Breed of animal, age, Management practice and season are significant risk factors associated with bovine dermatophilosis

The direct examination method was more sensitive than the culture technique for the diagnosis of bovine dermatophilosis.

Therefore, regular control of ectoparasites, early diagnosis, isolation and treatment of infected animals as well as culling of chronically infected animals that do not respond to treatment are recommended as measures for the prevention and control of the disease among the cattle population.

Furthermore, wearing personal protective equipment before handling affected animals and thorough washing of hands with antiseptic soap after contact with an infected animal is recommended for prevention of human exposure.

\section{Acknowledgments}

The authors are grateful to the technical staff, Department of Veterinary Microbiology, Faculty of Veterinary Medicine, Ahmadu Bello University, Zaria, Nigeria, for preparing the media used for this research.

\section{Conflicts of Interest}

The authors declare no conflict of interest.

\section{References}

Abdullahi US (2001). Chemotherapeautic and chemoprophylactic control of bovine dermatophilosis. Ph.D Thesis. Ahmadu Bello University, Zaria, Nigeria.

Abu-Samra MT (1978). Morphological, cultural and biochemical characteristics of Dermatophilus congolensis. Zoonoses and Public Health, 25(8): 668-688.

Adedeji OA \& Adene IC (2017). Streptothricosis (Dermatophilosis) infection in cattle. IOSR Journal of Agriculture and Veterinary Science, 10(8):41-43.

Admassu M \& Alemu S (2011). Study on clinical bovine dermatophilosis and its potential risk factors in north western Ethiopia. International Journal of Animal and Veterinary Advances, 3(1): 33-36.

Ambrose N, Lloyd D \& Millard JC (1999). Immune response to Dermatophilus congolensis 
infections. Parasitology Today, 15(7):295:300.

Amor A, Enrquez A Corcuera MT, Toro C, Herrero D \& Baquero M (2011). Is infection by Dermatophilus congolensis underdiagnosed? Journal of Clinical Microbiology, 49(1): 449-451.

Aubin G, Guillouzouic A, Chamoux C, Lepelletier D, Barbarot S. \& Corvec S (2016). Two family members with skin infection due to Dermatophilus congolensis: A case report and literature review. European Journal of Dermatology, 26(6): 621-622.

Awad WS, Nadre E, Abdou MI \& El-Sayed AA (2008). Diagnosis and treatment of bovine, ovine and equine dermatophilosis. Journal of Applied Sciences Research, 4(4):367-374.

Bayisa D, Berhanu A, Fantahun T \& Chanie M (2012). Occurrence of bovine dermatophilosis in Ambo town, west shoa administrative zone, Ethiopi. American-Eurasian Journal of Scientific Research, 7(4): 172-175.

Bida SA \& Kelley DC (1976). In Dermatophilus Infection in Animals and Man. Proceedings of a symposium held at the University of Ibadan, Nigeria. (DH Lloyd, KC Sellers, editors) academic press, London, Pp 229242.

Brian F \& Larry H (2013). Dermatophilosis in Sheep and Goats, Kansas State University.

Dalis JS, Kazeem HM, Makinde AA \& Fatihu MY (2007). Agalactia due to severe generalized dermatophilosis in a White Fulani cow in Zaria, Kaduna state. Vom Journal of Veterinary Science, 1(4): 56-58.

Dalis JS, Kazeem HM, Makinde AA, Fatihu MY. \& Dashe GY (2010). Bacteria associated with pathology of bovine dermatophilosis in north central Nigeria. Veterinary Research, 3(1): 4-8.

Gordon MA (1964). The Genus Dermatophilus. Journal of Bacteriology, 88(2):509-522.

Hargis AM. \& Myers S (2017). The integument. In J.F. Zachary (ed.). Pathologic bases of veterinary disease, sixthth edition. St. Louis, MO: Elsevier. Pp 1009-1146.

Kumar SK, Kavitha S, Selvaraj P, Sivakumar R, Kumar MR \& Yogeshpriya S (2018). Dermatophilosis in draught and dairy cattle in Tamil Nadu Delta Districts of India. Annals of Reviews and Research, 2(1):1-4.

Lunn T, Macgregor J \& Munks S (2016). Dermatophilus congolensis infection in Platypus (Ornithorhynchus anatinus),
Tasmania. Journal of Wildlife Diseases, 52(4): 965-967.

Macadam I (1976). In Dermatophilosis Infection in Animals and Man. International symposium on dermatophilosis, pp 33-42. University of Ibadan, Nigeria Academic Press London.

Makinde AA (2004). Dermatophilosis in animals and man: Recent studies on Dermatophilus congolensis. Vom Journal of Veterinary Science, 1(1): 87-108.

Mannan MA, Khan MRS, Rahman MM, Begum F \& Uddin MZ (2009). Isolation and identification of Dermatophilus congolensis from the skin lesions of cattle. Bangladesh Journal of Veterinary Medicine, 7(2): 342:347.

Martin SW, Meek AH \& Willeberg P (1997). Veterinary Epidemiology, Principles and Methods. Iowa State University Press, Ames, lowa

Maruthi, S.T., Prasad, C.K., Belakeri, P. Sagar, S.R. and Chethan, G.N. 2017. Diagnosis and treatment of bovine dermatophilosis. Intas Polivet, 18(1):85-87.

Moriello KA (2013). Dermatophilosis in animals. In Merck Veterinary Manual, National Publishing Inc. Eight ed, Philadelphia. Pp 613-615.

Nath BD, Ahasan S, Rahman S \& Huque F (2010). Prevalence and therapeutic management of bovine dermatophilosis. Bangladesh Research Publications Journal, 4(3):198-207.

Office International des Epizooties (2019). Dermatophilosis. Manual of Diagnostic Tests and Vaccines for Terrestrial Animals, Pp 725-727.

Oppong EMW (1976). Epizootiology of Dermatophilus infection in cattle in the Accra plains of Ghana. In: Dermatophilus Infection In animals and man. (Liyod, D.H. and Sellers, K.C., edition. Academic press, London. Pp 17-32.

Quinn PJ, Carter MEMarkey BK \& Carte GR (1999). Clinical Veterinary Microbiology. Harcourt Publishers Ltd. Edimburgh, London. Pp 153155.

Radostits OM, Gray CC, Hinchichiff KW \& Constable PD (2007). Veterinary Medicine, a Text Book of the Diseases of Cattle, Sheep, Pigs, Goats and Horses. Tenth edition. Philadelphia: Saunders; Pp 1048-1050.

Skalka B. \& Pospisil, L (1994). A standard method for demonstration of the life cycle of 
Dermatophilus congolensis. Acta Veterinaria Brno, 63(1): 3-7.

Siva PB. \& Vijaya SA (2015). Prevalence of bovine dermatophilosis Andhra Pradesh. International Journal of Food, Agriculture and Veterinary Science, 5(2): 64-71.

Dermatophilus Infection in Animals and Man. Proceedings of a symposium held at the University of Ibadan, Nigeria (DH Lloyd, KC Sellers, editors) Academic Press, London, Pp 202-211.
Thrusfield, M.V. (1997). Veterinary Epidemiology. second edition. Blackwell Publishing, Oxford, Great Britain.

Van Breuseghem R, Takashio M, Nagh MM, Presler $D$, Selly $M$ \& Van Wetter $P$ (1976). In:

Zaria LT (1993). Dermatophilus congolensis infection (Dermatophilosis) in animals and man. An update. Comparative Immunology and Microbial Infectious Diseases, 16(3): 179-22. 